\title{
A Study into the Development of a Light Weight Smart Life Buoy Prototype (LWSLB)
}

\author{
Suresh Thanakodi, Muhamad Lazim Talib, Syarifah Aishah \\ Syed Ali, Norshahriah Abdul Wahab, Amalina Farhi Ahmad, \\ Norshaheeda Mohd Noor, Muhammad Izham Bin Ahmad \\ Zahari, Mohd Arif Ahmad
}

Life Buoy, also known as a life preserver, is a crucial safety tool on board any marine ships. The most common and conventional lifesaver is operated manually to save people from drowning, yet this method poses a risk for both the victim and rescuer. Hence, with the help of current technology, a smart lifebuoy has been developed, whereby the rescuer just operates the lifebuoy using remote control. Yet, the existing smart life buoy system has been found heavy and hard to be operated, especially for women, children, and other people with disabilities.This paper focuses on the development of a lightweight smart life buoy system and its characteristics. Arduino Uno R3, Arduino Nano, DC motor 775, Transmitter and Receiver kit were the main components used in the development of the lightweight smart life buoy system (LWSLB). The developed LWSLB system was tested at the National

\section{KEY WORDS \\ $\sim$ Lifebuoy \\ $\sim$ Remote-control \\ $\sim$ Arduino \\ $\sim$ Drowning}

Universiti Pertahanan Nasional Malaysia, Kuala Lumpur, Malaysia

e-mail: suresh@upnm.edu.my

doi: 10.7225/toms.v10.n02.008

This work is licensed under (cc) BY

Received on: 28.06.2021/Revised on: 10.10.2021/Accepted on: 13.10.2021/Published: 21.10.2021
Defence University of Malaysia' swimming pool due to Covid-19 lockdown, and data such as speed, range of remote connection and battery endurance were obtained. It has been found out that the developed LWSLB weighs just $3.5 \mathrm{~kg}$ overall compared to Brand S which weighs $13.75 \mathrm{~kg}$. However, in terms of speed, Brand S proves to be faster at $4.17 \mathrm{~m} / \mathrm{s}$ compared to LWSLB which exhibits a speed of $1.25 \mathrm{~m} / \mathrm{s}$.

\section{INTRODUCTION}

Globally, drowning is rather common (Zhu, Jiang, Li and Chen, 2015) and, according to the World Health Organization (WHO), drowning fatalities are a neglected public health issue, ranked as the third most frequent cause of unintentional death by injury (Nyitrai, Edwards and Dwyer, 2019). Unintentional drowning occurs in diverse locations such as lakes, rivers, and coastlines (Celia et al., 2018). It also happens in various weather conditions and affects both adults and children (Celia et al., 2018). Generally, drowning is referred to as the process of submersion or immersion in liquid to experience respiratory impairment (Zhu, Jiang, Li and Chen, 2015). Therefore, flotation has become a device that plays an important role in saving lives.

Personal flotation devices and life preservers, such as lifebuoys, have been used on various watercraft for many years during emergencies (Mitev, 2020). For example, a lifebuoy may be released from the watercraft into the water towards the person overboard during a man overboard (MOB) situation in which a person has unintentionally fallen out of the watercraft and into 
the surrounding water (Mitev, 2020). Once the lifebuoy has been launched into the water towards the person overboard, the lifebuoy is hopefully within the reach of the person overboard; if not, it is often more difficult to rescue the person overboard (Mitev, 2020).

In the current era, lifebuoy can be categorized into two types known as manual lifebuoy and smart lifebuoy. The manual lifebuoy is a conventional one, such as the lifebuoy ring that is a doughnut-shaped (Collins, 2017). The utilization of manual life buoy seems to be practical when the victim is not far from the rescuer's place. This is because manual lifebuoy can only reach the victims according to the strength of the rescuer who is throwing the ring and in certain drowning situations, at least one person may have to descend into the water with the life ring to rescue the victim (Mitev, 2020). For man overboard situations, a person needs to guide the lifebuoy towards the overboard man as it is usually not accurate when the lifebuoy is thrown towards the victim (Mitev, 2020) However, the scenario can be challenging and risky for the rescuer, even with good swimming skills during bad weather or in a rocky place.

As a life-saving alternative, the introduction of technology to lifebuoy has given birth to a smart lifebuoy. It can be best presented as a remote-control, mostly U-shaped lifebuoy (Collins, 2017). Smart lifebuoys are able to reach the far victim by utilizing remote-control thumb-stick that can be conducted by the rescuer (Collins, 2017). This technology avoids the danger and risk for the rescuer from descending into the water to save the victim. However, the existing smart lifebuoy system has been found too heavy and hard to be operated, especially for women, children, and other people with disabilities. Hence, this may jeopardize the rescue mission during an emergency of man overboard situations. Therefore, there is a high niche for the development of a lightweight remote-control lifebuoy system.

For the purpose of this paper the researcher has used Arduino technology for the development of a light-weight life buoy prototype. Arduino is open-source software for designing and programming electronics (Badamasi, 2014). There are plenty of advantages in using Arduino, such as the components consisting of a small circuit which reduces the size of the prototype (Varesano, 2011), affordable cost (Watelectronics, 2021), user-friendly (Varesano, 2011), facilitating multiple input and output. Unfortunately, it is not a waterproof device, therefore, the developed Arduino circuit has to be placed in a waterproof casing to ensure the board and electronics components' safety from exposure to water.

In this research work the developed LWSLB uses remotecontrol technology. Remote-control technology is a wireless power transmission system that includes a transmitter and a receiver for the signal transmission and receiving process (Terada, Shinoda and Yamamoto, 2014). The transmitter consists of a power transmission unit for powering the transmitter, as well as a communication module (Terada, Shinoda and Yamamoto, 2014). On the other hand, the receiver unit on the smart lifebuoy is able to receive signals from the transmitter unit using a power receiving unit (Terada, Shinoda and Yamamoto, 2014). The received data signal then enables the water pump to turn on as the water pump acts as the thruster for the buoy. The thrust happens through the pull and pushes mechanism, whereby the water pump pulls the water inwards and pushes it out in another outlet with pressure, producing the thrust needed for the buoy, while turning left or right according to the rescuer's signal from the remote controller.

Based on practicality, the remote-control life buoy device is more efficient to be used in rescuing a drowning person. It reduces the risk of the rescuer from also turning to be a victim. Observation also concludes that remote-control lifebuoy may shorten the time for a rescue operation, and it is also user friendly to be conducted by anyone from shore or on board a ship. Generally, remote-controlled lifebuoy or also known as smart lifebuoy stands a better chance of saving people's life compared to conventional lifebuoy.

\section{METHODOLOGY}

Figure 1 summarizes the overall process in accomplishing the research work. The prototype designing process has been carried out based on a literature review by focusing on the weight reduction of the existing remote-controlled lifebuoy. For this research work, two different working prototype models have been developed and analyzed. Both of the developed LWSLB use Arduino technology as a mainboard. Components such as Arduino Nano, L298N driver, transmitter, receiver board, motor, and $12 \mathrm{~V}$ Lithium Polymer battery, have been selected and utilized on both prototypes.

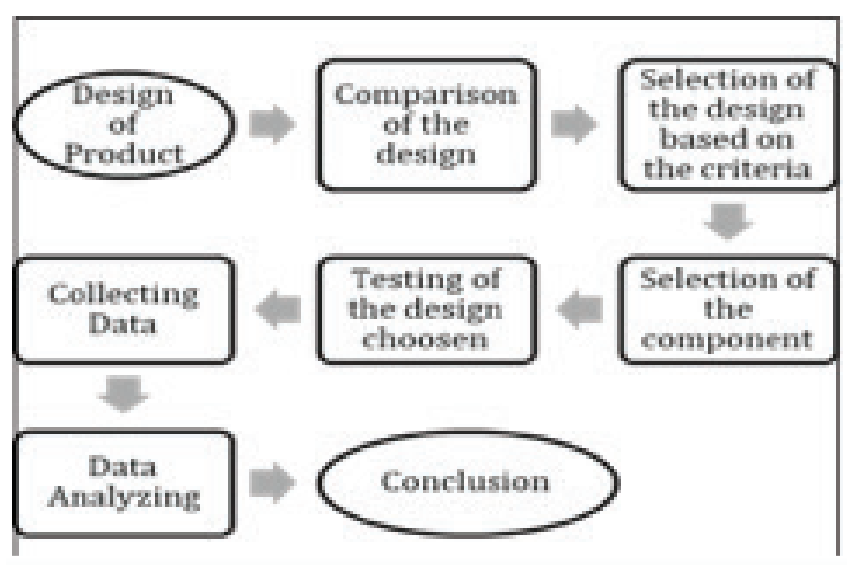

Figure 1.

Flowchart of procedure. 
Both developed LWSLB have been later tested and their functionality verified in the swimming pool located in the National Defence University of Malaysia due to the Covid-19 Movement Control Order. The best-designed prototype has then been determined and its performances described in terms of speed, loading weight, battery endurance, and range for the remote-control connection. Further enhancing the analysis, the obtained data have been compared with the industrial existing smart lifebuoy. As a final process, conclusions have been drawn based on the research objectives and findings from the experiment.

\subsection{Design Constructed}

Figure 2 shows Prototype $X$, developed from kickboard, polyvinyl chloride (PVC) pipe, rubber hose, and electronic components. In this prototype, the Arduino board and electronics components have been located on the left side of the white coloured PVC pipe to ensure the electronics components sealed from contact with water. The thrust for Prototype $X$ is achieved through the differences in water pressure created by the water pump through a water inlet rubber hose under the PVC pipe and water outlet at the upper rubber hose.

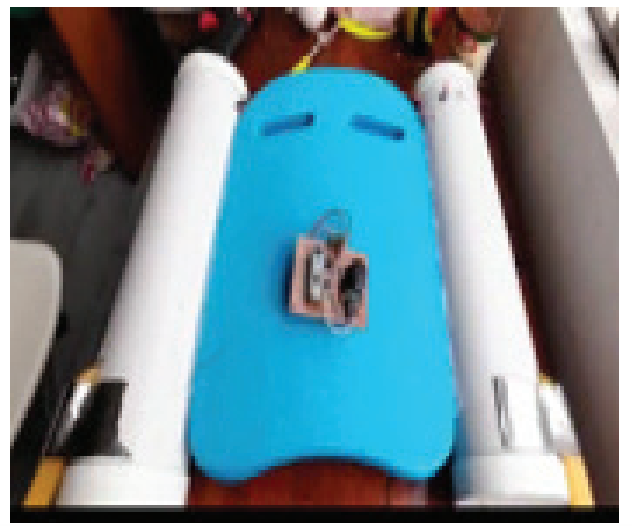

Figure 2.

Prototype X.

Figure 3 shows the second design, constructed using similar materials and the same electronic boards and components, but with an addition of used mineral bottles. In this design, the Arduino board and electronic components were secured inside the mineral bottles to prevent contact with water. All the openings in the bottle were sealed using a water-resistant sealant. In comparison with the previous design, the thrust for Prototype $Y$ generated through water pressure pushed out from both ends of PVC using the 775-motor controlled by the L298N motor driver. The 12V 775 DC Motor has a speed of 2200 rotation per minute (rpm) and a torque of $350 \mathrm{~g}-\mathrm{cm}$ at a maximum efficiency. The 775 DC motor has been chosen due to its characteristics of high speed (torque).

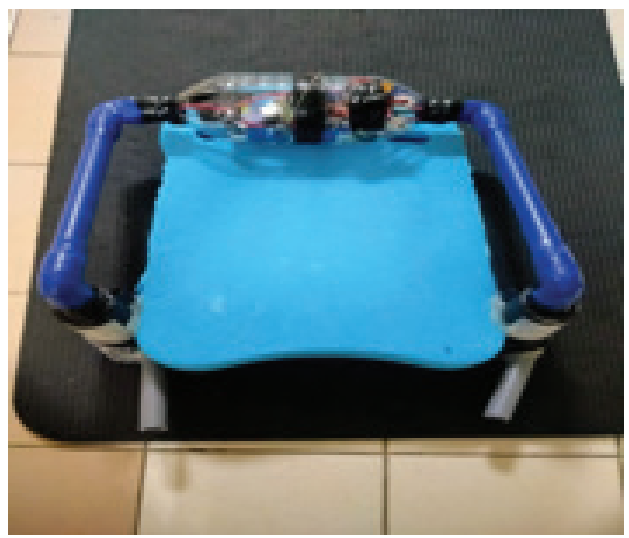

Figure 3.

Prototype Y.

\subsection{Comparison Between Design and Speed Characterization}

In comparison to Prototype $\mathrm{Y}$, Prototype $\mathrm{Y}$ has been found to be heavier as the design uses bigger PVC pipes on both sides of the kickboard to host the electronic components. The electronic components in Prototype $\mathrm{X}$ are located inside of one of the PVC pipes, which causes instability for the overall lightweight smart life buoy system, compared to Prototype Y. This is due to the design of Prototype $Y$ which houses the electronic components in a bottle at the front, balancing and distributing the weight between the left and right side accordingly. Furthermore, the Prototype $Y$ exhibits more ergonomic design which enables the user to easily hop on to during the rescue mission. Hence, with all due considerations and comparisons between the two designs, Prototype $Y$ has been found to be better and is therefore used throughout the experiment for the characterization process.

In order to obtain the speed and average speed for Prototype $\mathrm{Y}$, the formulae below have been used in this experimental work, whereas the results are discussed in Section 3.3.

$$
\text { Speed, } v=\frac{\text { distance, } d}{\text { time,t }}
$$

Average speed $=\underline{(\text { Speed for } 10 m+S p e e d \text { for } 25 m+\text { Speed for } 50 m)}$ 3 


\subsection{Remote Control Construction}

Figure 4 shows the schematic diagram constructed using Proteus 8 application for the transmitter and receiver module of the smart lifebuoy system. The diagram consists of Arduino uno R3, Arduino nano, switch, motor, and power supply. Figure 4 clearly depicts the separation between the transmitter and receiver module, whereby many components attached to the receiver are compared to the transmitter.

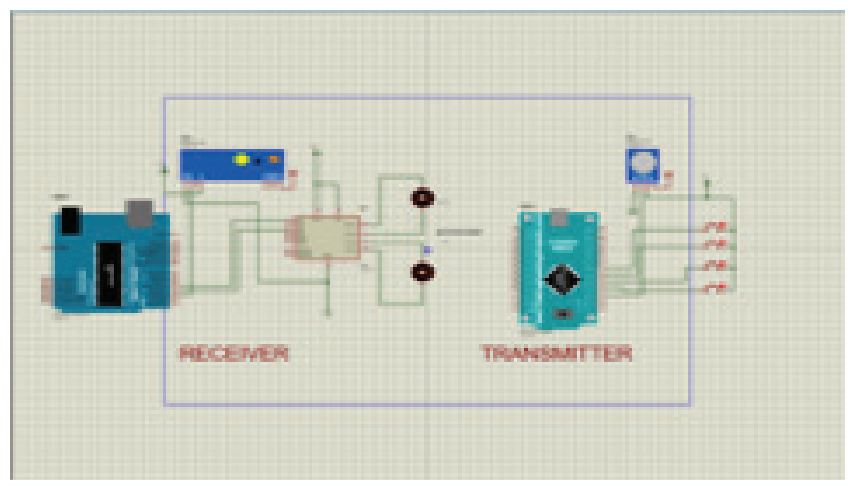

Figure 4.

Schematic Diagram of Remote-Control for LWSLB.
The transmitter's simple design is due to the functionality of a basic remote control in order to facilitate its use and to create user-friendly features for the rescuer. On the other hand, the receiver module, located on the lifebuoy, consists of other relevant components such as switch, motor, power supply and etc. The coding for the operation of the lifebuoy system has been carried out using Arduino software platform known as Arduino Integrated Development Environment (IDE) and uploaded to the board via computing order to facilitate the USB connection.

\section{RESULTS}

\subsection{Comparison Between Types of Life Buoy System}

Table 1 summarizes the comparison between the types of lifebuoys currently in existence and in the market usage. The manual life buoy (life ring) and the developed Prototype $Y$ can be categorized as light weight lifebuoy compared to the existing smart life buoy. Light weight lifebuoy enables the rescuer to dispatch it faster during an emergency and this may indirectly help the survivability of the victim. On the other hand, the existing smart lifebuoy (Brand S) and the developed Prototype $Y$ exhibit more ability compared to the life-ring in terms of rescuing range. The smart life buoy rescuing range has been determined by the range of remote-control connection, while the manual life buoy (life ring) is based on the rescuer's muscle strength.

Table 1.

Types of Life Buoy in Comparison.

\begin{tabular}{llll} 
Characteristics & $\begin{array}{l}\text { Manual Life Buoy } \\
\text { (Life Ring) }\end{array}$ & $\begin{array}{l}\text { Existing Smart Life Buoy } \\
\text { (Brand S) }\end{array}$ & $\begin{array}{l}\text { Developed Light Weight Smart } \\
\text { Life Buoy (LWSLB) } \\
\text { (Prototype Y) }\end{array}$ \\
\hline Weight & $\begin{array}{l}\text { Light } \\
(2.5 \mathrm{~kg}-4.3 \mathrm{~kg})\end{array}$ & $\begin{array}{l}\text { Heavy } \\
(13.75 \mathrm{~kg})\end{array}$ & $\begin{array}{l}\text { Light } \\
(3.50 \mathrm{~kg})\end{array}$ \\
\hline Rescuing Range & Based on human's strength & $\begin{array}{l}\text { Based on a range of remote- } \\
\text { control connection }\end{array}$ & $\begin{array}{l}\text { Based on a range of remote- } \\
\text { control connection }\end{array}$ \\
\hline Provided Support System & NIL & $\begin{array}{l}\text { Allows the victim rest on the } \\
\text { lifebuoy }\end{array}$ & $\begin{array}{l}\text { Allows the victim rest on the } \\
\text { lifebuoy }\end{array}$ \\
\hline Accuracy to Reach Victims & $\begin{array}{l}\text { Less accurate for long-range } \\
\text { distance victim \& depends on } \\
\text { the environmental factors too }\end{array}$ & $\begin{array}{l}\text { Able to reach the victim at any } \\
\text { conditions }\end{array}$ & $\begin{array}{l}\text { Able to reach the victim at any } \\
\text { conditions }\end{array}$ \\
\hline Risk Assessment & $\begin{array}{l}\text { Both to the victim and the } \\
\text { rescuer }\end{array}$ & Victim only & Victim only \\
\hline
\end{tabular}

In addition to the rescuing range factor, the accuracy of lifebuoy in reaching the victim is also crucial, whereby the smart lifebuoy is able to reach the victim accurately in any weather conditions as it is remotely controlled and uses the motor technology to manoeuvre towards the victim. While the manual life buoy has many challenges in reaching the victim, as it does not have any maneuvering capabilities and is easily affected by the water current directions. This may result in high possibilities 
of losing the victim and in such condition requires the rescuer's direct involvement by descending into water for the rescuing purposes. Hence, utilizing smart life buoy system, reduces the risk of losing a number of lives compared to the manual life buoy, whereby both the victim and the rescuers are at a risk of drowning.

\subsection{Cost Comparison Between Smart Life Buoy System}

Table 2 summarizes the detailed cost incurred for the development of a lightweight smart lifebuoy system (Prototype $Y)$. The detailed components, with a total cost for the current smart life buoy available in the market (Brand S), is impossible to present since this research work is a self-funded work and the cost to obtain it quite high. Overall cost of Brand $\mathrm{S}$ is estimated to be at $€ 2,795.56$, while the developed Prototype $Y$ costs around $€ 47.60$. Yet, it is expected that this cost might increase by $20 \%$ if Prototype $\mathrm{Y}$ is to be commercialized as there will be an aesthetic upliftment, especially in replacement of mineral water bottle housing the electronic boards. In terms of money, Prototype $Y$ looks promising and affordable for any normal fisheries ship to own it, while Brand $\mathrm{S}$ is for a high-end user. However, further analysis carried out on the Prototype $Y$ performance and comparison between Brand $\mathrm{S}$ has also been presented in the next section.

Table 2.

Cost Comparison between Brand S and Prototype $\mathrm{Y}$.

Brand Qty.
Existing Smart Life Buoy System

\section{Apparatus}

12V Motor 775 for Water Pumping

Arduino Uno R3

Arduino Nano

L298N Motor Driver

Transmitter and Receiver Module Kit

Li-Po Battery 12V 4200mah 1

9V Battery

Kickboard

PVC Pipe with Elbow

Mineral Bottle

Total Cost

2

1

1

1

1

(Brand S)

$€ 2,795.56$

\section{Developed LWSLB \\ (Prototype Y)}

$€ 12.42$

$€ 4.95$

$€ 3.00$

$€ 1.43$

$1 \quad € 1.22$

$€ 17.59$

$1 \quad € 1.01$

$1 \quad € 3.08$

$2 \quad € 0.62$

\subsection{Characterization of Performance on Developed} LWSLB (Prototype Y)

Table 3 summarizes the test results for average speed characterization of Prototype Y. The characterization test was conducted at the National Defence University of Malaysia's swimming pool due to the Covid-19's Movement Control Order. The swimming pool has a maximum length of 50 meter with a depth of 2 meters and the tests have been repeated thrice for each length range. The average speed for each test range have then been averaged out by using the formula discussed in Section 2.2. While for the speed test there is no specific apparatus, the basic Galileo's formula, as stated in Section 2.2, has been used, helping to obtain the speed attained by Prototype $\mathrm{Y}$.

Table 3.

Results on Average Speed Obtained by Prototype Y.

\begin{tabular}{lll} 
Range & Time Taken & Speed \\
\hline $10 \mathrm{~m}$ & $7.81 \mathrm{~s}$ & $1.28 \mathrm{~m} / \mathrm{s}$ \\
\hline $25 \mathrm{~m}$ & $20.16 \mathrm{~s}$ & $1.24 \mathrm{~m} / \mathrm{s}$ \\
\hline $50 \mathrm{~m}$ & $40.65 \mathrm{~s}$ & $1.23 \mathrm{~m} / \mathrm{s}$ \\
\hline Average Speed & $1.25 \mathrm{~m} / \mathrm{s}$ & \\
\hline
\end{tabular}


Therefore, using this technique the rest speed tests have been obtained by varying the distance travelled by Prototype $Y$ and duration (time) taken using a stopwatch. As the observation made from Table 3 shows, there is a slight reduction in speed from Prototype $Y$ as the distance increases. One of the reasons causing such scenario would be human error in obtaining the time taken since it is manually done, using a stopwatch. This is due to the longer distance the Prototype $Y$ travels: the human mind become less alert and comfortable with the situation, hence there is a slight delay between the eyes and hand coordination using the stopwatch in gathering the data for time.

Another possible reason for the situation might be due to motor thrust in the first ten (10) metres that accelerates before reaching its normal speed and this is caused by high current during the start-up of the motor. Both error factors have been mitigated in this experiment by averaging out the speed with various distance, resulted in average speed of $1.25 \mathrm{~ms}-1$ for the developed Prototype Y. The average speed, as shown in Table 3, has been obtained by using the average formula discussed in section 2.2

Table 4 summarizes the results obtained from various criteria of life buoy such as its weight, speed, and load carrier. For smart life buoy, three (3) important criteria were experimented upon: battery endurance, range of remote-control connections, and the life buoy speed. The performance comparison between the developed Prototype $Y$ against the current lifebuoy in the market has also been presented in Table 4. Certainly, a manual life buoy, light in weight and able to lift up to $200 \mathrm{~kg}$ of load, but highly dependent on the life-savers skill and rescuing experiences, hence increases the risk of losing life of both the victim and rescuers.

Table 4

Performance Comparison of Various Life Buoy

\begin{tabular}{ll} 
Brand & $\begin{array}{l}\text { Manual Life Buoy } \\
\text { (Life Ring) }\end{array}$ \\
\hline Characteristics & Life
\end{tabular}

\section{Weight}

Speed

Load Carrier

Battery Endurance

Range of Remote-Control Connection

\section{Existing Smart Life Buoy} (Brand S)

\section{Developed Light Weight Smart Life Buoy (Prototype Y)}

$3.5 \mathrm{~kg}$

$1.25 \mathrm{~m} / \mathrm{s}$

$100 \mathrm{~kg}$

12 minutes

50 meters
The developed Prototype $Y$ weights $3.5 \mathrm{~kg}$ and manages to reduce the smart life buoy weight by $74.5 \%$ in comparison to Brand $\mathrm{S}$, the existing in the current market. However, the marketed Brand S smart life buoy has a higher speed and longer battery endurance compared to Prototype Y. This is due to the utilized number of motors, type of motor and battery used in Brand S compared to Prototype Y. The type of motor and their number plays a major role in creating the thrust, resulting in speed, while a higher capacity battery is able to supply power for a longer duration of time. Brand $\mathrm{S}$ is propelled by two (2) electric motors to power up its turbine, while prototype $Y$ uses only one motor to create the water pressure necessary for its thrust.

In designing Prototype $\mathrm{Y}$, the reduction of weight and cost were the major consideration, hence, with the budgeted cost, small power type of motor have been used in order to reduce the weight, as well as a smaller capacity battery. This explains the reason behind the poor performance of Prototype $Y$ compared to
Brand $\mathrm{S}$ in terms of speed and duration of battery usage. Brand $\mathrm{S}$ has nearly $83.3 \%$ advantages compared to Prototype $Y$ in terms of remote connectivity. The ability for a longer range of remote connectivity depends highly on the technology used, whereby Brand S uses Bluetooth 4.2 and Wi-Fi technology, increasing the range for its remote connection, while Prototype $Y$ uses Arduino Radio Frequency (RF) transmitter and receiver module. Monetary factor also plays a vital role in the development of Prototype Y. Although there are some disadvantages of the developed prototype in comparison to Brand S, Prototype $Y$ has succeeded in becoming a lightweight smart lifebuoy and could possibly be used in short range rescue missions.

\section{CONCLUSION}

In conclusion, the introduction of smart lifebuoy technology complements the usage of manual lifebuoy and has clearly 
exhibited more advantages, mainly in reducing the risks of losing life during search and rescue operations. Prototype $Y$ has been successfully developed to become a fully functional lightweight smart life buoy system; however, with a reduced performance in comparison to the product currently existing in the international market. The developed prototype can be used in s short-range rescue mission with an affordable price for everyone to own it. On the other hand, improvements can be made towards the number of motors utilized and types of motors for gaining a higher speed life buoy system. In addition, using a higher capacity Lithium Polymer (LiPo) battery can extend the functional duration of the life buoy and it is also recommended to use a broader kickboard to increase the ability to carry higher loads. All things considered, the objective of this paper has been achieved by presenting the development and characterization of the lightweight smart life buoy system (Prototype Y).

\section{REFERENCES}

Allied Components, 2016. 14 Essential Electronic Components and their Functions. Available at: https://www.alliedcomponents.com/blog/essential-electroniccomponents-functions, accessed on: 12 January 2021.

Badamasi, Y.A., 2014. The working principle of an Arduino. 2014 11th International Conference on Electronics, Computer and Computation (ICECCO). Available at: http://dx.doi.org/10.1109/icecco.2014.6997578.

Collins, A., 2017. U-SAFE: This Remote Controlled Life Buoy is super fast in saving lives. Available at: https://factschronicle.com/u-safe-this-remote-controlled-lifebuoy-is-super-fast-in-saving-lives-4619.html, accessed on: 24 January 2021.

EIProCus, 2019. Water Pump: Working principle, Types and Their Applications. Available at: https://www.elprocus.com/water-pump-types-and-applications, accessed on: 12 January 2021.
GrandOcean, 2020. Lifebuoy Ring, Life Float Ring Manufacturer. Available at: https://www.grandoceanmarine.com/marine-safety-equipments/life-float-lifebuoy/, accessed on: 12 January 2021.

Kumar, A., 2020. Difference Between Centrifugal pump and Reciprocating pump. Available at: https://learnmechanical.com/difference-between-centrifugal-pumpand-reciprocating-pump, accessed on: 12 June 2020.

Lin, Y.-N. et al., 2020. Development and verification of a smart remote control system for home appliances. Computers \& Electrical Engineering, 88, p.106889. Available at: http://dx.doi.org/10.1016/j.compeleceng.2020.106889.

Mitev, G., 2020. Autonomous Lifebuoy. US20200148320A1.

Nyitrai, N., Edwards, S. \& O'Dwyer, N., 2019. Drowning Prevention: Define and Then Gather Evidence or Gather Evidence to Define? International Journal of Aquatic Research and Education, 10(4). Available at:

http://dx.doi.org/10.25035/ijare.10.04.01.

Ridden, P., 2019. Remote-controlled lifebuoy propels itself to save troubled swimmers. Available at: https://newatlas.com/dolphin-oceanalpha-remote-electriclifebuoy/60586/, accessed on: 12 June 2020.

Seguin, C. et al., 2018. Unmanned aerial vehicles (drones) to prevent drowning. Resuscitation, 127, pp.63-67. Available at: http://dx.doi.org/10.1016/j.resuscitation.2018.04.005.

Terada, T., Shinoda, H. and Yamamoto, K., 2014. Wireless power transmission system, transmitter, and receiver. US8892033B2.

Varesano, F., 2011. What is Arduino, Why we choose it, what can we do with it? Available at: http://www.varesano.net/blog/fabio/, accessed on: 12 January 2021.

Watelectronics, 2021. Arduino Technology Architecture and its Applications. Available at: https://www.watelectronics.com/arduino-technology-architectureand-applications/, accessed on: 12 January 2021.

Zhu, Y., Jiang, X., Li, H. and Chen, J., 2015. Mortality among drowning rescuers in China, 2013: a review of 225 rescue incidents from the press. BMC Public Health, 15(631). 